\title{
PENGALIHAN PIUTANG SECARA CESSIE ATAS PEMBIAYAAN DENGAN JAMINAN HAK TANGGUNGAN PADA PERBANKAN SYARI'AH : SUATU TELAAH HUKUM ISLAM DAN PRINSIP PERBANKAN SYARI'AH
}

\author{
Agung Pribadi \\ Mahasiswa Program Magister Hukum USM
}

\begin{abstract}
ABSTRAK
Utang piutang sering kali tidak dapat dihindari karena sangat kental dengan kehidupan manusia. Demikianlah keadaan manusia sebagaimana Allah SWT tetapkan, ada yang dilapangkan rezekinya hingga berlimpah ruah dan ada pula yang dipersempit rezekinya, tidak dapat mencukupi kebutuhan pokoknya sehingga mendorongnya dengan terpaksa untuk berhutang. Sehingga diperlukan pengetahuan bagaimana kaidah utang piutang menurut syariat. Salah satu kaidah yang harus diketahui adalah kaidah : "menjual hutang dengan hutang adalah batal. Dalam karya ini, penulis akan mencoba memaparkan judul "pengalihan piutang secara cessie atas pembiayaan dengan jaminan hak tanggungan pada perbankan syariah: suatu telaah hukum islam dan prinsip perbankan syariah". Berdasarkan dari penelitian tersebut bahwa: pertama implementasi sistem cessie tersebut tidak terkecuali dalam dalam mendukung sistem perbankan syariah. Dalam perspektif hukum islam nilai yang dikedepankan adalah kemaslahatan, hal ini pula yang harus diterapkan dalam implementasi cessie, kedua Keberadaan cessie sebagai wujud pengalihan piutang tentunya merupakan implikasi terhadaphak tanggungan kepada debitur. Hal ini tentunya harus dikedepankan nilai nilai keadilan sehingga implikasi yang ditimbulkan tidak memunculkan aspek kemadhorotan bagi para pihak.
\end{abstract}

Kata kunci: Pengalihan Piutang,Cessie dan Perbankan Syariah.

\section{CESSIE RECEIVABLES TRANSFER ON THE FINANCING WITH THE WARRANTY OF LIABILITY ON SYARI'AH BANKING: A STUDY ON IS- LAMIC LAWS AND SHARIAAH BANKING PRINCIPLES}

\author{
Agung Bribadi \\ Mahasiswa Program Magister Hukum USM
}

\begin{abstract}
Debt and receivables are often unavoidable because it is so close to human life. Thus, as Allah Almighty set, some are expanded sustenance to abundant and some are narrowed sustenance, they cannot meet the basic needs so encouraged by forced to indebted. So it takes knowledge of how the rules of accounts payable according to the Shari'a. One of the rules is: "to sell debt with debt is void. In this work, the researcher will try to explain the title of "cessie receivable transfer of financing with warranty of liability guarantee on sharia banking: a study on Islamic law and sharia banking principles". Based on the research, there are several issues come up: the first implementation of the
\end{abstract}


cessie system is no exception in supporting the sharia banking system. In the perspective of Islamic law, the value that is put forward is the benefit, this also should be applied in the implementation of cessie. The second, the existence of cessie as a form of transfer of receivables, it is an implication to liability to the debtor. We must be put forward the values of justice, so that the implications that arise do not bring the bad aspect for the parties.

Keywords: Transfer of Receivables, Cessie and Sharia Banking.

\section{PENDAHULUAN}

\section{A. Latar Belakang Penelitian}

Sebagai mahluk sosial tentunya manusia tidak dapat hidup sendiri dan selalu membutuhkan bantuan orang lain untuk memenuhi kebutuhan hidupnya, terutama dalam hal muamalah, seperti jual beli, pinjam meminjam, sewa menyewa hingga urusan utang piutang maupun usaha- usaha yang lain, baik dalam urusan diri sendiri maupun untuk kemaslahatan umum.Namun sering kali dalam kehidupan sehari-hari banyak kita temui kecurangankecurangan pada permasalahan muamalah ini, seperti riba yang memberatkan.

\section{Perbankan Syariah kini} menjadi salah satu alternatif pilihan ditengah kebutuhan masarakat akan layanan perbankan. (Arab:
الم المرف بية

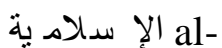

Mashrafiyah al-Islamiyah) adalah suatu sistem perbankan yang pelaksanaannya berdasarkan hukum Islam (syariah). Pembentukan sistem ini berdasarkan adanya larangan dalam agama Islam untuk meminjamkan atau memungut pinjaman dengan mengenakan bunga pinjaman (riba), serta larangan untuk berinvestasi pada usaha-usaha berkategori terlarang (haram)1.

Sehubungan dengan fasilitas kredit yang diterima oleh debitur tersebut, debitur pada umumnya diminta untuk menyerahkan jaminan tertentu kepada Bank guna menjamin pelunasan hutangnya kepada Bank. Pasal 1131 KUHPerdata mengatakan bahwa

1 Rammal, H. G., Zurbruegg, R.

(2007). Awareness of Islamic Banking Products Among Muslims: The Case of Australia. dalam Journal of Financial Services Marketing, Hal. 65. 
setiap kebendaan seseorang, baik yang berupa benda bergerak maupun tidak bergerak, baik yang sudah ada maupun yang akan ada di kemudian hari, merupakan tanggungan untuk segala perikatan perseorangan, dan merupakan jaminan atas seluruh hutanghutangnya. $^{2}$

Dengan adanya pemberian jaminan secara khusus yang menjamin pelunasan hutang debitur kepada kreditur maka kreditur akan memiliki hak preferen di dalam mengambil pelunasan atas piutangnya daripada para kreditur lainnya. Untuk kemudahan dan kepastian pelaksanaanya eksekusi obyek hak tanggungan, pelaksanaan pembebanan Hak Tanggungan hendaknya memenuhi prosedur asas spesialitas ${ }^{3}$ dan asas publisitas $^{4}$ agar keberadaan lem-

2 Satrio, Cessie, Subrogatie, Novatie, Kompensatie \& Percampuran Hutang, cet. 2, Bandung; Alumni, 1999, hal. 2.

3 Asas spesialitas adalah bahwa untuk sahnya Akta Pembebanan Hak Tanggungan, akta tersebut harus mencantumkan secara lengkap hal-hal yang disebutkan di dalam Pasal 11 ayat (1) UUHT, yaitu baik mengenai subjek, objek, maupun hutang yang dijamin haruslah dicantumkan secara jelas. (Penjelasan Pasal 11 ayat (1) UUHT).

4 Asas publisitas adalah bahwa agar Hak Tanggungan memberikan kedudukan diutamakan kepada kreditur maka harus ada catatan baga jaminan Hak Tanggungan tersebut dapat secara efektif mengakomodasi kebutuhan kreditur di dalam mengamankan kredit yang disalurkan kepada masyarakat.

Perkembangan yang terjadi di sektor sosial dan ekonomi, baik dalam skala nasional maupun internasional, secara langsung maupun tidak langsung dapat mempengaruhi keadaan likuiditas serta kebijakan penyaluran kredit pada Bank selaku kreditur. Akibatnya, tidak jarang dalam kurun waktu berlakunya perjanjian kredit, Bank selaku kreditur berkeinginan untuk mengundurkan diri dari partisipasinya. Pengunduran diri kreditur tentu saja akan dapat mempengaruhi kegiatan usaha yang dilakukan oleh debitur apabila dana yang dipergunakan untuk melakukan kegiatan usaha tersebut berasal dari fasilitas kredit bank. Agar kegiatan pendanaan yang diterima oleh debitur tidak terhenti begitu

mengenai Hak Tanggungan tersebut pada buku tanah dan sertipikat hak atas tanah yang dibebaninya sehingga setiap orang dapat mengetahuinya (Penjelasan Pasal 4 ayat (1) UUHT). 
saja, maka dikenal lembaga pengalihan piutang yang dilakukan dengan cara Cessie.

Adanya suatu tagihan disebabkan karena debitur tertentu berhutang kepada kreditur tertentu. Hal ini didasari oleh ketentuan Pasal 1338 KUHPerdata dimana dikatakan bahwa setiap perjanjian yang dibuat secara sah berlaku sebagai undang-undang bagi para pihak yang membuatnya. Dalam perbuatan pengalihan piutang, debitur tidak memiliki peran yang aktif. Akan tetapi di dalam pasal 613 KUHPerdata ditetapkan bahwa penyerahan atau pengalihan piutang baru mempunyai akibat dan mengikat debitur setelah penyerahan atau pengalihan piutang tersebut diberitahukan kepada debitur atau secara tertulis disetujui dan diakui oleh debitur. Dengan demikian, hal mengenai pengalihan piutang itu haruslah diberitahukan kepada debitur agar perjanjian pengalihan piutang dan segala akibat hukum yang ditimbulkannya memberikan akibat kepada debitur yang bersangku$\tan$.
Dari uraian-uraian di atas, tampak bahwa cessie merupakan suatu cara untuk mengalihan piutang atas nama tanpa mengakibatkan perjanjian kredit/ pinjam meminjam uang yang mengakibatkan timbulnya piutang tersebut menjadi hapus.

\section{B. Perumusan Permasalahan}

Berdasarkan latar belakang penelitian tersebut diatas, dirumuskan permasalahan penelitiannya, yakni sebagai berikut:

$$
\begin{aligned}
& \text { 1. Bagaimana pengalihan } \\
& \text { piutang dengan cessie atas } \\
& \text { hak tanggungan menurut } \\
& \text { sudut pandang hukum islam } \\
& \text { dan perbankan syariah? }
\end{aligned}
$$
2. Bagaimana implikasi hukum dari dilakukanya pengalihan piutang dengan cessie atas hak tanggungan kepada debitur?

\section{Tujuan Penelitian.}

Berangkat dari pokok permasalahan tersebut di atas, maka secara keseluruhan tujuan penelitian ini adalah : 
1. Untuk memahami dan menganalisis pengalihan piutang dengan cessie atas pembiayaan dengan jaminan hak tanggungan sesuai dengan hukum islam dan perbankan syariah.

2. Untuk memahami dan menganalisis implikasi penerapan pengalihan piutang dengan cessie atas pembiayaan dengan jaminan hak tanggungan terhadap debitur.

\section{Kegunaan Penelitian}

Hasil penelitian ini nantinya diharapkan dapat memberikan manfaat antara lain:

1. Secara umum, penelitian diharapkan sebagai bahan perbandingan bagi peneliti lainnya yang ingin mengkaji permasalahan yang serupa atau aspek lainnya dimasa mendatang.

\section{Secara Teoretis}

Hasil penelitian ini diharapkan dapat memberikan masukan bagi perkembangan hukum per- bankan, khususnya pada perbankan syariah dalam memberikan fasilitas pembiayaan dan pengalihan piutang dengan menggunakan cessie.

\section{Secara Praktis}

Melalui penelitian ini mencoba untuk mengungkap kesesuaian terhadap syariat islam dan dampak-dampak hukum terhadap dilakukanya pengalihan piutang dengan cessie atas pembiayaan dengan jaminan hak tanggungan.

\section{Tinjauan Pustaka}

\section{A. Perbankan Syariah}

Undang-undang No. 10 Tahun 1998 tentang Penyempurnaan Undang-undang No.7 Tahun 1992 tentang Perbankan merupakan langkah maju dalam perkembangan perbankan, terutama bagi perbankan syariah ${ }^{5}$;

Dengan disahkannya Undang-undang No. 21 tahun 2008

\footnotetext{
${ }^{5}$ Dr. Abdul Halim Ismail, Islamic Fund Manager, paper dipresentasikan dalam Lokakarya Ulama tentang Reksadana, Holiday Inn, Jakarta, 29-30 Juli 1997.
} 
tentang Perbankan Syariah telah membuka kesempatan lebih luas bagi bank syariah untuk berkembang.

Riba dilarang dalam segala bentuknya bahkan dalam ayat Alquran tentang pelarangan riba yang terakhir yaitu surat $\mathrm{Al}$ Baqarah ayat 278-279 secara tegas dinyatakan yang artinya sebagai berikut;

"Hai orang-orang yang beriman takutlah kepada Allah dan tinggalkanlah sisa-sisa riba itu jika kamu orang beriman. Kalau kamu tiada memperbuatnya ketahuilah ada peperangan dari Allah dan RasulNya terhadapmu dan jika kamu bertobat maka untukmu pokok-pokok hartamu kamu tidak menganiaya dan tidak pula teraniaya."

\section{B. Prinsip-prinsip Cessie}

Cessie adalah salah satu cara pengalihan dan atau penyerahan piutang atas nama sebagaimana yang dimaksud pada Pasal 613 Kitab Undang-Undang Hukum Perdata (KUHPerdata). Namun demikian, kata cessie tid- ak terdapat di dalam undangundang yang berlaku di Indone$\operatorname{sia}^{6}$.

Di Indonesia, definisi Cessie salah satunya dikemukakan oleh Subekti. Menurut pendapat Subekti, Cessie adalah: "Suatu cara pemindahan piutang atas nama dimana piutang itu dijual oleh kreditur lama kepada orang yang nantinya menjadi kreditur baru, namun hubungan hukum utang piutang tersebut tidak hapus sedetikpun, tetapi dalam keseluruhannya dipindahkan kepada kreditur baru"7 Dengan tegas, Pasal 613 KUHPerdata menyebutkan bahwa piutang yang diatur di dalam pasal 613 KUHPerdata adalah piutang atau tagihan atas nama. Dalam tagihan atas nama, debitur mengetahui dengan pasti siapa krediturnya. Salah satu ciri khas yang dimiliki oleh suatu tagihan atas nama adalah bahwa tagihan atas nama tidak memiliki wujud, walaupun dibuatkan suatu surat hutang, maka su-

\footnotetext{
${ }^{6}$ Loc.Cit,Satrio, hal. 10.

${ }^{7}$ Subekti. Hukum Perjanjian. Cet.17. Jakarta: Intermasa, 1998.
} 
rat hutang hanya berlaku sebagai alat bukti saja.

Sahnya Cessie Dalam penyerahan piutang atas nama dengan cara cessie terdapat tiga pihak yaitu Cedent sebagai kreditur lama yang memiliki tagihan piutang atas nama, kemudian Cessionaris sebagai kreditur baru yang menerima pengalihan piutang atas nama dan Cessus sebagai debitur dalam hal ini hanya sebagai pihak yang menerima pemberitahuan atau memberikan persetujuan atas perjanjian cessie yang dibuat antara cedent dengan Cessionaris.

\section{Hak Tanggungan}

Sebelum berlakunya UUPA (Undang-Undang Pokok Agraria), dalam hukum dikenal lembagalembaga hak jaminan atas tanah yaitu,jika yang dijadikan jaminan tanah hak barat, seperti Hak Eigendom, Hak Erfpacht atau Hak Opstal, lembaga jaminannya adalah Hipotik, sedangkan Hak Milik dapat sebagai obyek Credietverband. Dengan demikian mengenai segi materilnya mengenai Hipotik dan Credietverband atas tanah masih tetap berdasarkan ketentuan-ketentuan KUH Perdata dan Stb 1908 Nomor 542 jo Stb 1937 Nomor 190 yaitu misalnya mengenai hak-hak dan kewajiban yang timbul dari adanya hubungan hukum itu mengenai asas-asas Hipotik, mengenai tingkatan-tingkatan Hipotik janji-janji dalam Hipotik dan Credietverband ${ }^{8}$. Dengan berlakunya UUPA, (UU Nomor 5 Tahun 1960) maka dalam rangka mengadakan unifikasi hukum tanah, dibentuklah hak jaminan atas tanah baru yang diberi nama Hak Tanggungan, sebagai pengganti lembaga Hipotik dan Credietverband dengan Hak milik, Hak Guna Usaha dan Hak Guna Bangunan sebagai obyek yang dapat dibebaninya Hak-hak barat sebagai obyek Hipotik dan Hak Milik dapat sebagai obyek Credietverband tidak ada lagi, karena hak-hak tersebut telah dikonversi menjadi salah satu hak baru yang diatur dalam UUPA. 
Hasil Penelitian dan Analisis

\section{A. Pengalihan Piutang Dengan}

Cessie Atas Hak Tanggungan

Menurut sudut Pandang

Hukum Islam Dan Perbankan

Syariah

Secara bahasa pengalihan hutang dalam hukum islam disebut sebagai hiwalah yang mempunyai arti lain yaitu $\mathrm{Al}$ intiqal dan Al-tahwil, artinya adalah memindahkan dan mengalihkan Penjelasan yang dimaksud adalah memindahkan hutang dari tanggungan muhil (orang yang berhutang) menjadi tanggungan muhal'alaih (orang yang melakukan pembayaran hutang ${ }^{9}$.

Sedangkan pengertian $\mathrm{Hi}$ walah secara istilah, para Ulama' berbeda-beda dalam mendefinisikannya, antara lain sebagai berikut:

1. Menurut Hanafi, yang dimaksud hiwalah ${ }^{10}$ :

"Memidahkan tagihan dari tanggung jawab yang beru-

\footnotetext{
${ }^{9}$ H.Atang Abd., 2012, Hakim Fiqh Perbankan Syariah: Tranformasi Fiqih Muamalah Kedalam Peraturan Perundang-undangan, Bandung, PT.Refika Aditama, Hal. 282.

${ }^{10}$ Ibid.
}

tang kepada yang lain yang punya tanggung jawab pula”.

2. Al-jaziri berpendapat bahwa yang dimaksud dengan Hiwalah adalah:

$$
\begin{aligned}
& \text { "Pemindahan utang dari } \\
& \text { tanggung jawab seseorang } \\
& \text { menjadi tanggung jawab } \\
& \text { oranglain". }
\end{aligned}
$$

3. Syihab al-din al-qalyubi bahwa yang dimaksud dengan Hiwalah adalah:

"Akad yang menetapkan pemindahan beban utang dari seseorang kepada yang lain”.

4. Muhammad Syatha aldimyati berpendapat bahwa yang dimaksud Hiwalah adalah:

"Akad yang menetapkan pemindahan utang dari beban seseorang menjadi beban orang lain”.

5. Ibrahim al-bajuri berpendapat bahwa Hiwalah adalah: 
"Pemindahan kewajiban

dari beban yang memin-

dahkan menjadi beban

yang menerima peminda-

han".

6. Menurut Taqiyuddin, yang dimaksud Hiwalah adalah:

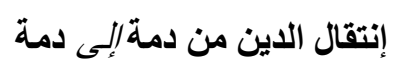

"Pemindahan utang dari beban seseorang menjadi beban orang lain".

Hiwalah dibolehkan berdasarkan Sunnah dan Ijma' ${ }^{11}$ :

1. Hadits

Imam Bukhari dan Muslim meriwayatkan dari $\mathrm{Abu}$

Hurairoh, bahwa Rasulullah saw, bersabda:

"Memperlambat pembayaran hukum yang dilakukan oleh orang kaya merupakan perbuatan zalim. Jika salah seorang kamu dialihkan kepada orang yang mudah membayar hutang, maka hendaklah ia beralih(diterima pengalihan tersebut)".(HR Jama'ah)

${ }^{11}$ Sayyid Sabiq, 1986,Fiqih Sunnah,terj. Kammaludin, Bandung,Al-Maarif, Hal.42.
Pada hadits ini Rasulullah memerintahkan kepada orang yang menghutangkan, jika orang yang berhutang menghiwalahkan kepada orang yang kaya dan berkemampuan, hendaklah ia menerima hiwalah tersebut, dan hendaklah ia mengikuti (menagih) kepada orang yang dihiwalahkannya (muhal'alaih), dengan demikian hakknya dapat terpenuhi (dibayar).

2. Ijma'

Para ulama sepakat membolehkan hawalah. Hawalah dibolehkan pada hutang yang tidak berbentuk barang/ benda, karena hawalah adalah perpindahan utang, oleh sebab itu harus pada utang atau kewajiban financial.

Secara umum jaminan dalam hukum Islam (fiqh) dibagi menjadi dua, jaminan yang berupa orang (personal guarancy) sering dikenal dengan istilah kafalah dan 
jaminan yang berupa harta benda dikenal dengan istilah rahn ${ }^{12}$.

a. Kafalah

Kafalah menurut etimoligi berarti Aldhamanah, Hamalah dan Za'aamah, Ketiga istilah tersebut memiliki arti yang sama, yakni menjamin atau menanggung, sedangkan menurut terminology Kafalah adalah jaminan yang diberikan oleh Kafiil ( penanggung) kepada pihak ketiga atas kewajiban atau prestasi yang harus diberikan ditunaikan pihak kedua ( tertanggung ).

\section{b. Rahn.}

Secara etimologi, kata ar-rahn berarti tetap, kekal, dan jaminan Akad arrahn dalam istilah hukum positif disebut dengan barang jaminan. Sedangkan

${ }^{12}$ Wahbah Zuhaili, Al-Fiqh al-Islamy wa Adillatuhu, (Beirut: Dar al-Fikr, 2002), cet. 6, hal. 4141 menurut ulama madzhab Maliki istilah ar-rahn adalah Harta yang dijadikan pemiliknya sebagai Obyek ja$\operatorname{minan}^{13}$.

B. Implikasi

Hukum

Dilakukannya

Pengalihan

Piutang Dengan Cessie Atas Hak Tanggungan Kepada Debitur

Cessie adalah salah satu cara pengalihan dan atau penyerahan piutang atas nama sebagaimana yang dimaksud pada Pasal 613 Kitab Undang-Undang Hukum Perdata (KUHPerdata). Namun demikian, kata cessie tidak terdapat di dalam undangundang yang berlaku di Indone$\operatorname{sia}^{14}$.

Bagi bank syariah, untuk kasus anjak piutang, bank dapat memberikan fasilitas pengambilalihah piutang, yaitu yang disebut hiwalah. Tetapi untuk fasilitas ini pun bank tidak dibenarkan meminta imbalan kecuali biaya layanan atau biaya administrasi

${ }^{13}$ Ibnu 'Abidin, Radd al-Muhktar 'ala ad-Durr al-Mukhtar, (Beirut: Dar al-Fikr, 1963), Jilid V, hal. 339, lihat juga As Sarakhsi, al Mabsut, (Beirut: Dar al Fikr, tt.), Jilid XXI, hal. 63

${ }^{14}$ Loc.Cit,Satrio, hal. 10. 
dan biaya penagihan. Dengan demikian, bank syariah meminjamkan uang (qardh) sebesar piutang yang tertera dalam dokumen piutang (wesel tagih atau promes) yang diserahkan kepada bank - tanpa potongan. Selain itu, sebagian ulama memberikan jalan keluar berupa pembelian surat hutang (bai' al dayn), tetapi sebagian ulama melarangnya, tapi jika bank meminta imbalan maka dampaknya merugikan debitur dan cara seperti itu dilarang oleh syari'ah.

\section{PENUTUP}

\section{A. Kesimpulan}

1. Pengalihan piutang secara cessie atas pembiayaan dengan jaminan hak tanggungan merupakan instrumen bagian terpenting dalam mendukung sistem ekonomi nasional, implementasi sistem cessie tersebut tidak terkecuali dalam dalam mendukung sistem perbankan syariah. Dalam prospektif hukum islam nilai yang dikedepankan adalah kemaslahatan, hal ini pula yang harus diterapkan dalam implementasi cessie.

2. Implikasi Hukum dilakukannya Pengalihan Piutang Dengan Cessie atas Hak Tanggungan Kepada Debitur mengakibatkan pengalihan piutang yang dilakukan oleh kreditur lama kepada pihak ketiga tidaklah mengakibatkan berakhirnya perjanjian kredit yang telah dibuatnya dengan debitur. Perjanjian Kredit yang telah dibuat diantara debitur dan kreditur yang mengakibatkan timbulnya piutang yang dialihkan itu tetap berlaku dan mengikat bagi debitur dan bagi pihak ketiga selaku kreditur yang baru, Syarat-syarat cessie dalam KUHPerdata belum memenuhi keseluruhan syarat pembentukan akad cakupannya sangat luas, belum tentu sesuai dengan ketentuan syariat hukum islam yang harus terbebas dari unsur larangan yakni 
riba, maysir, dan gharar/

penipuan. Sehingga kalau

dalam konsep hukum islam

maka akan lebih

diperhatikannya dalam

mafsadat dan maslahahnya /

kemanfaatannya. Hal ini

tentunya harus

dikedepankan nilai - nilai

keadilan sehingga implikasi

yang ditimbulkan tidak

memunculkan aspek

kemadhorotan bagi para

pihak.

\section{B. Saran}

1. Bagi pemerintah ikut aktif mengawasi sistem cessie apabila diterapkan pada perbankan syari'ah

2. Perlu adanya penguatan perundang - undangan utamanya terkait diberlakukanya sistem cessie yang ada diperbankan syari'ah.

3. Masyarakat ikut terlibat dalam pengawasan sistem cessie khususnya ketika masyarakat mengagunkan sesuatu di perbankan syaria'ah dan kemudian Bank Syariah tersebut mengalihkannya dengan sistem cessie.

\section{Daftar Pustaka Buku}

Abdul Halim Ismail, Islamic Fund Manager, paper dipresentasikan dalam Lokakarya Ulama tentang Reksadana, Holiday Inn, Jakarta, 29-30 Juli 1997

H.Atang Abd., 2012, Hakim Fiqh Perbankan Syariah: Tranformasi Fiqih Muamalah Kedalam Peraturan Perundangundangan, Bandung, PT.Refika Aditama

Ibnu 'Abidin, Radd al-Muhktar 'ala adDurr al-Mukhtar, (Beirut: Dar al-Fikr, 1963), Jilid V, hal. 339, lihat juga As Sarakhsi, al Mabsut, (Beirut: Dar al Fikr, tt.), Jilid XXI

Rammal, H. G., Zurbruegg, R. (2007). Awareness of Islamic Banking Products Among Muslims: The Case of Australia. dalam Journal of Financial Services Marketing

Satrio, Cessie, Subrogatie, Novatie, Kompensatie \& Percampuran Hutang, cet. 2, Bandung; Alumni, 1999

Sayyid Sabiq, 1986,Fiqih Sunnah,terj. Kammaludin, Bandung,AlMaarif

Sri Soedewi Masjehoen, Hak Jaminan Atas Tanah,Liberty: Yogyakarta, 1975 
Subekti. Hukum Perjanjian. Cet.17. Jakarta: Intermasa, 1998

Wahbah Zuhaili, Al-Fiqh al-Islamy wa Adillatuhu, (Beirut: Dar alFikr, 2002), cet. 6 
